\title{
Dissolved oxygen modeling of an urban stream using grid partitioning and subtractive clustering fuzzy techniques
}

\author{
Sameer Arora ${ }^{1}$ \\ ${ }^{1}$ Indian Institute of Technology Delhi
}

April 10, 2021

\begin{abstract}
Dissolved oxygen is one of the prime parameters for assessing the water quality of any stream and the health status of aquatic life. The dissolved oxygen present in the water body plays an essential role in deciding water treatment processes to enhance water quality up to the design standards for the specified water use. Thus, the accurate estimation of dissolved oxygen concentration is necessary to evolve measures for maintaining the riverine ecosystem and designing the appropriate water treatment plants. Machine learning techniques are becoming useful tools for the prediction and simulation of water quality parameters. With these viewpoints, a study was carried out in the Delhi stretch of Yamuna River, India, and physiochemical parameters were examined for five years to simulate the dissolved oxygen using different machine learning techniques. Simulation and prediction competencies of ANFIS grid partitioning (ANFIS-GP) and ANFIS subtractive clustering (ANFIS-SC) were tested on various water quality parameters. Variation in dissolved oxygen was examined on various combinations of parameters. ANFIS-GP has been designed using the Gaussian function, and ANFIS-SC works on the likelihood of cluster centers. Results obtained from the models were evaluated using root mean square error (RMSE) and coefficient of determination (R2) to identify the optimum solution and appropriate combination of parameters that simulate the observed dissolved oxygen. Results of ANFIS-GP and ANFIS-SC indicate that both the models produce suitable solutions for the prediction; however, ANFIS-GP outperforms the ANFIS-SC and could act as a useful tool for defining, planning, and management of water quality parameters.
\end{abstract}

\section{Hosted file}

Full Paper.pdf available at https://authorea.com/users/406925/articles/517406-dissolvedoxygen-modeling-of-an-urban-stream-using-grid-partitioning-and-subtractive-clusteringfuzzy-techniques

\section{Hosted file}

LIst of Figures.pdf available at https://authorea.com/users/406925/articles/517406-dissolvedoxygen-modeling-of-an-urban-stream-using-grid-partitioning-and-subtractive-clusteringfuzzy-techniques 